\title{
Inflorescence morphology of some Australian Lasiopetaleae (Sterculiaceae)
}

\author{
C. Bayer and K. Kubitzki
}

\begin{abstract}
Bayer, C. and Kubitzki, K. (Institut für Allgemeine Botanik und Herbarium der Universität Hamburg, Ohnhorststr. 18, 22609 Hamburg, Germany) 1996. Inflorescence morphology of some Australian Lasiopetaleae (Sterculiaceae). Telopea 6(4): 721-728. The inflorescence morphology of 17 species out of five genera of the tribe Lasiopetaleae (Sterculiaceae) is investigated. The flowering shoots are sympodia composed of modules bearing several foliage leaves and a terminal inflorescence. In the inflorescences, metatopic displacements can be noted. The basic type, as represented by Keraudrenia, is identified as a cymoid with two lateral dichasia. In Thomasia, Hannafordia, Guichenotia and Lysiosepalum, the inflorescences are cincinnoid. The three-bracteate epicalyx, which is found beneath each flower in these monochasial inflorescences, is homologous with a sterile bract and the two subtending bracts of the lateral cymes in Keraudrenia. The relatively primitive inflorescence structure of Keraudrenia links the predominently Australian tribe Lasiopetaleae with the pantropical tribe Byttnerieae.
\end{abstract}

\section{Introduction}

The Australian representatives of the tribe Lasiopetaleae (Sterculiaceae) exhibit different inflorescence types. In the taxonomic literature there are no indications how these forms are connected with each other and with the inflorescences of other members of the Sterculiaceae and Malvales. Due to the lack of precise characterisations it is not possible to use inflorescence characters for taxonomic comparisons, even less to polarize them.

Only few taxonomists have attempted to take full advantage of characters provided by inflorescence morphology. This may be due to several reasons: the analysis of inflorescence structure is often complicated; a part of the relevant literature is written in languages other than English, and the different approaches and terminologies in use make the observations reported in the literature difficult to compare. Nevertheless, not only in comparative morphological studies, but also in taxonomic descriptions, a clear and precise terminology for the analysis of inflorescence characters should be used, as the one elaborated by Troll (1964, see also Weberling 1989) or Briggs \& Johnson (1979).

Indications in the morphological literature with respect to position and structure of the inflorescences of the Lasiopetaleae are confusing and contradictory. According to Gay (1821), the inflorescences are cymose, corymbose, racemose and sometimes leaf-opposed. Guichenotia ledifoila Gay is described as having an 'inflorescentia intrafoliacea'. According to Payer (1857), the basic inflorescence type of Lasiopetalum is found in the 'dichasia' of L. 'corylifolium', in which each flower is thought of as being provided with two fertile bracts. Baillon (1870) denies the occurrence of leafopposed inflorescences in the Lasiopetaleae. Since the position of the inflorescence is said to be not exactly leaf-opposed, he assumes that the unusual arrangement can be explained by displacements, following his interpretation of the inflorescences of Byttneria (Sterculiaceae-Byttnerieae). According to Eichler (1878), the flowers are arranged in cymes or in aggregates composed of cymes, and Schumann (1895) describes them as terminal or leaf-opposed in some genera. 
In the systematic literature, various of these views have been adopted. In Thomasia, for example, the position of the inflorescence is described as axillary or subterminal (Hutchinson 1967, Patrick 1993), or as terminal or leaf-opposed (Bentham \& Mueller 1863, Paust 1974, Jessop 1986). The inflorescence is called a raceme (Bentham \& Mueller 1863, Hutchinson 1967, Paust 1974, Jessop 1986, Patrick 1993), which contrasts with Wydler's (1878) and Eichler's (1878) interpretation as a cincinnus.

A detailed recent morphological analysis of the inflorescences of Lasiopetalum species by Classen (1988) reveals the sympodial character of the shoots and the structure of individual modules. She also discusses the problematic appendages forming an epicalyx ('bracts' or 'bracteoles subtending the flower' of other authors) and applies Troll's (1964) typological concepts to the synflorescences of Lasiopetalum.

In view of the inconsistencies found in the literature a re-examination of the inflorescences of Australian Lasiopetaleae seemed appropriate. Since Lasiopetalum had been analysed by Classen (1988), our work focussed on the other genera of the tribe.

\section{Material}

The material studied was very kindly provided by Dr. R. Classen-Bockhoff (Aachen, Germany), Prof. F. Weberling (Ulm, Germany), and the Directors of the Muséum National d'Histoire Naturelle (P), Royal Botanic Gardens Kew (K), and Botanical Museum Berlin-Dahlem (B) to whom we extend our sincerest thanks. It includes fluid fixed and herbarium specimens of the following species:

Guichenotia ledifolia Gay, G. macrantha Turcz., G. micrantha (Steetz) Benth., G. sarotes Benth.; Hannafordia bissillii F. Muell.; Keraudrenia collina Domin, K. hermanniifolia Gay, $K$. integrifolia Steudel; Lysiosepalum involucratum (Turcz.) C.A. Gardner; Thomasia discolor Steudel, T. foliosa Gay, T. grandiflora Lindley, T. petalocalyx F. Muell., T. quercifolia (Andrz.) Gay, T. rhynchocarpa Turcz., T. sarotes Turcz., T. solanacea Gay.

A list of specimens studied and their collecting localities has been deposited at the Royal Botanic Gardens Sydney or can be obtained from the authors.

\section{Observations}

The flowering shoots of all members of the Lasiopetaleae investigated are sympodia. Following Halle et al. (1978), the repeating units of a sympodium will be named 'module' in this article. Each module comprises one or more nodes with foliage leaves and a terminal inflorescence. This is overtopped by the axillary product of the most distal foliage leaf, leading to a leaf-opposed position of the inflorescence (Fig. 1). As usually only one axillary shoot continues the growth of the sympodium, a monochasium results.

The number of foliage leaves per module is variable even within one individual (cf. Keraudrenia hermanniifolia), but some species appear to produce predominantly more (e.g. often six in Guichenotia micrantha) or less (e.g. often two in Thomasia) leaves per module. Guichenotia ledifolia has stipules resembling foliage-leaves, giving the impression of a whorl consisting of three 'leaves' and an inflorescence.

In species like Thomasia quercifolia (Fig. $2 \mathrm{~A}$ ), the terminal inflorescence is well differentiated before it is overtopped by the next module, hence the sympodial character of the whole shoot is obvious. However, the subsequent bud may sprout precociously in some species. Sometimes an accessory bud is found in the axil of the leaf subtending the next module (Fig. 2 B: ac). Strictly axillary inflorescences have not been observed 

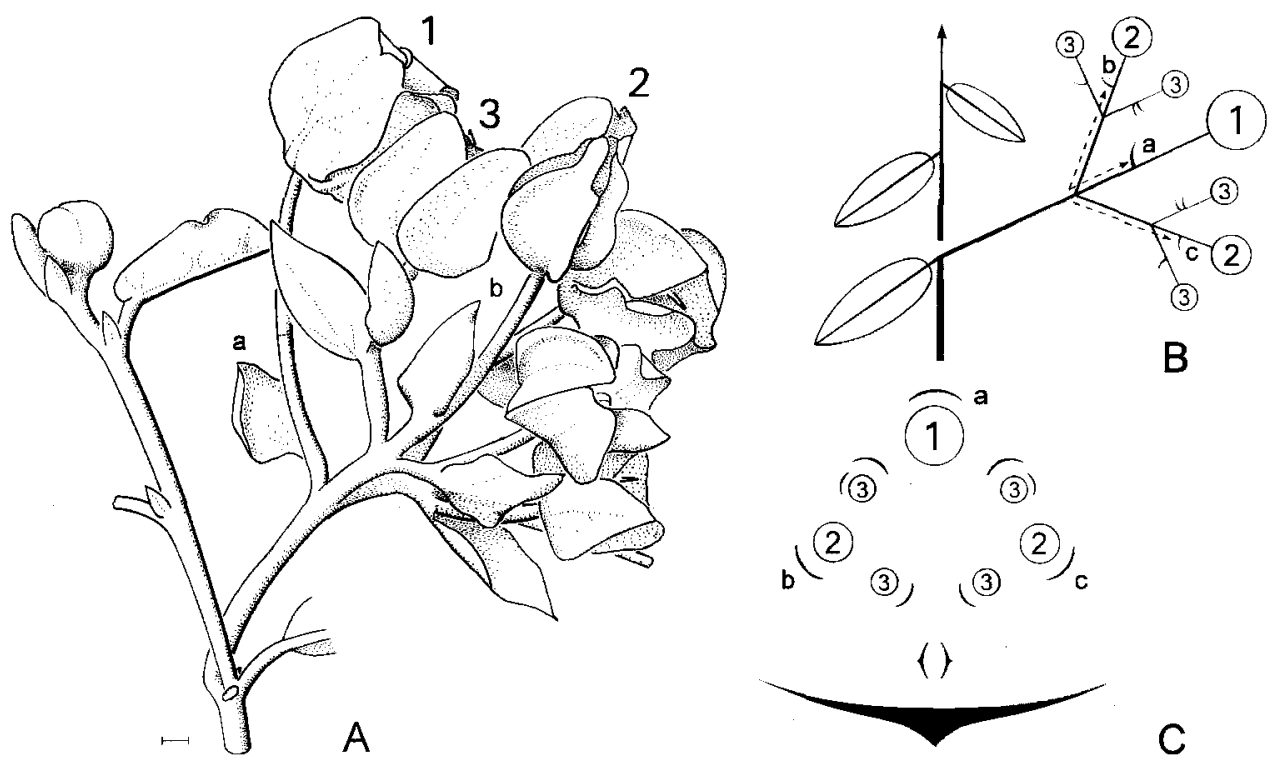

Fig. 1. Keraudrenia hermanniifolia Gay, A, distal part of a flowering sympodium with leaf-opposed inflorescence, bar: $1 \mathrm{~mm}$; $\mathbf{B}$, branching scheme; $\mathbf{C}$, diagram, numbers indicate the order of flowers (1: terminal flower); letters indicate bracts ( $\mathrm{a}$ is sterile, $\mathrm{b}$ and $\mathrm{c}$ subtend lateral cymes), some third order flowers with single prophyll, broken lines indicate ontogenetic displacements of the bracts.
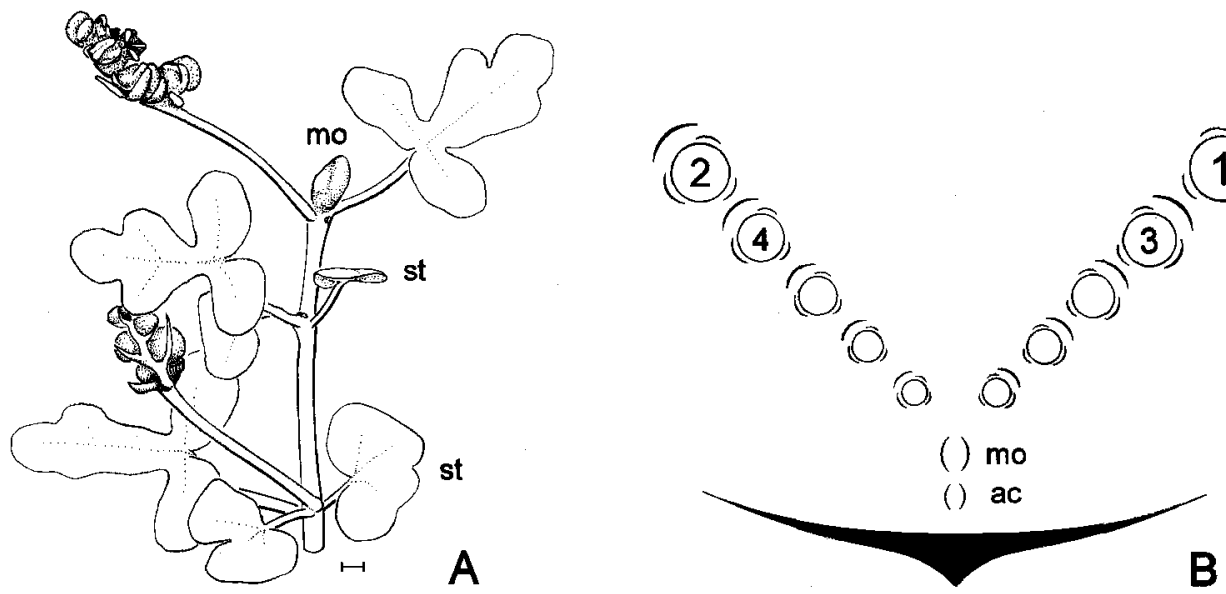

Fig. 2. Thomasia quercifolia (Andrz.) Gay, A, sympodium with leaf-opposed inflorescences, st stipule; note that stipules of the distal leaf subtending the bud of the subsequent module (mo) are removed, bar: $1 \mathrm{~mm}$; $\mathbf{B}$, diagram of an inflorescence with bud of subsequent module (mo) and accessory bud (ac). 


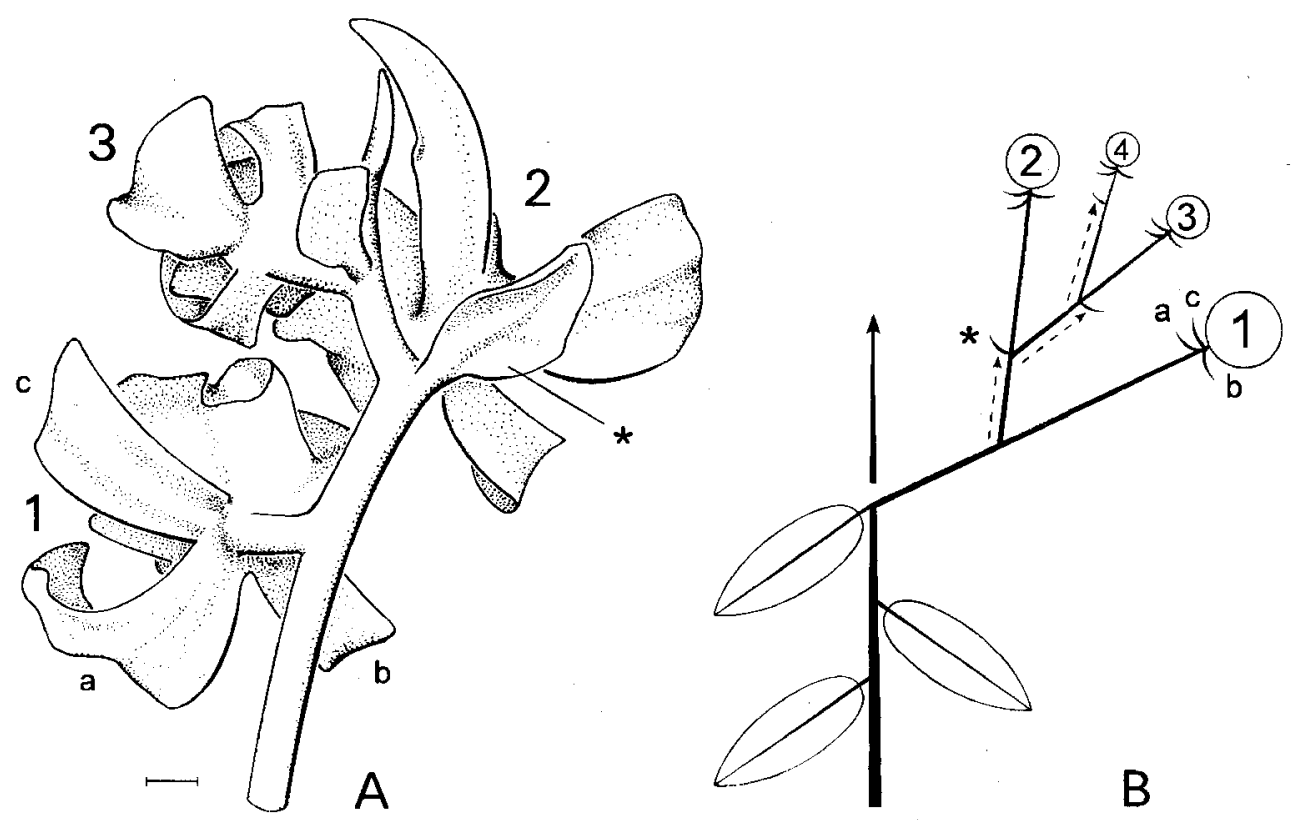

Fig. 3. A, inflorescence of Thomasia discolor Steud., bar: $1 \mathrm{~mm}$; B, basic branching scheme of the modules of Thomasia, Hannafordia, Guichenotia, and Lysiosepalum; numbers indicate the order of flowers, a, b, c: epicalyx of the terminal flower (1), broken lines indicate displacements, star: displaced subtending bract of the second flower (2).
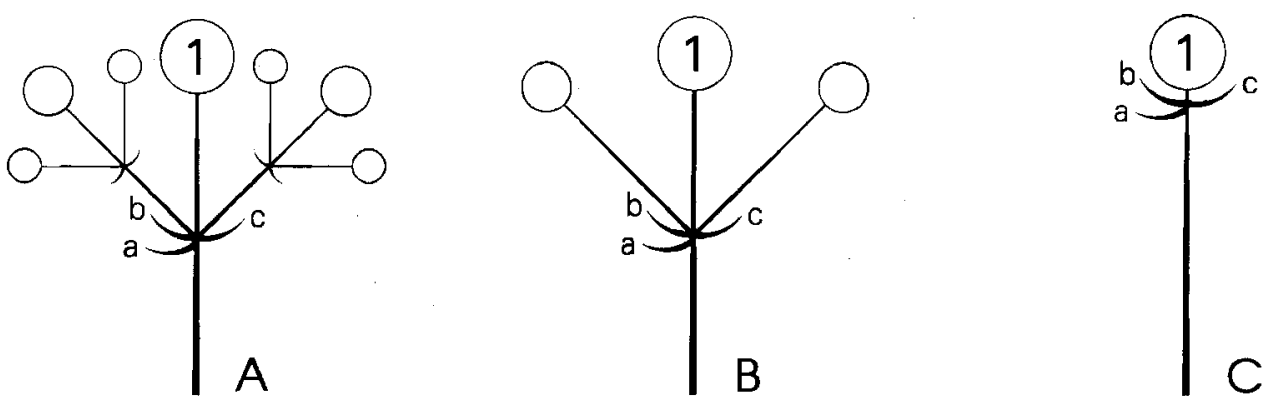

Fig. 4. Units of malvalean inflorescences with three bracts $(a, b, c)$ on the axis terminated by the first flower (1); A, complete unit with sterile bract (a) and two lateral cymes arising from the axils of $\mathbf{b}$ and $c ; \mathbf{B}$, three-flowered unit, $\mathbf{a}$ is sterile, $\mathbf{b}$ and $\mathrm{c}$ subtend single flowers; $\mathbf{C}$, Single flower with epicalyx of three sterile bracts $(a, b, c)$. 
in any species, but axillary shoots which start flowering without producing extensive vegetative zones may give the impression of axillary inflorescences.

The inflorescences of the Lasiopetaleae are structurally not homogeneous. In Keraudrenia hermanniifolia (Fig. 1) the inflorescence comprises a terminal flower (1) and two lateral, cymose partial inflorescences. In comparison with other Lasiopetaleae studied, this represents the most complete ramification pattern. In early developmental stages the main inflorescence axis bears three bracts, which during the development of the inflorescence change their original positions. One of these bracts is shifted upward on the main axis beyond the nodes from which the lateral cymes branch off; the axil of this bract remains empty (a). The two other bracts, which subtend cymose partial inflorescences, are displaced beyond the prophyllar nodes of their axillary products $(b, c)$. These displacements (metatopies) to a more distal position on the axis can be specified as recaulescence sensu Troll (1964).

The inflorescences of all other Lasiopetaleae investigated (Thomasia, Hannafordia, Guichenotia, Lysiosepalum) are terminal monochasia with more or less pronounced metatopies between subtending bracts and their axillary flowers (Fig. 3). Beneath each flower an epicalyx of three bract-like appendages is usually found, which encloses the flower in bud. In few-flowered inflorescences like those of Thomasia discolor (Fig. $3 \mathrm{~A}$ ), the sympodial character can easily be detected. The first flower to open (1) is the only one devoid of a subtending bract. This indicates that it is the terminal flower of the whole inflorescence. The subtending bract of the second flower (2) can not be traced at the branching point between the stalk of the terminal flower and the rest of the inflorescence. It is situated further distally (arrow), so that a recaulescent displacement has to be stated again. Accordingly, the subtending bract of the next flower (3) is displaced as well. If this type of ramification is repeated several times, many-flowered monochasia will result (e.g. Thomasia quercifolia, Fig. 2, and T. solanacea, T. rhynchocarpa). Other species (T. discolor, Fig. 3 A, T. sarotes, T. petalocalyx, T. foliosa) and representatives of other genera (Hannafordia, Guichenotia, Lysiosepalum: Fig. $3 \mathrm{~B}$ ) exhibit the same basic type of inflorescence ramification.

\section{Discussion}

In most Lasiopetaleae investigated, the inflorescence is clearly terminal. The leafopposed position of the inflorescences is a consequence of the sympodial shoot structure. If the stipules resemble foliage leaves, the wrong impression of an 'inflorescentia intrafoliacea' (Gay 1821) may result. The additional bud in the axil of the foliage leaf, which subtends the subsequent module (Fig. 2 B), is interpreted as a serial accessory bud. However, it cannot be excluded that it originated from a displaced and reduced basal ramification from a prophyllar axil of the subsequent module. Axillary inflorescences have not been observed. Therefore indications in the taxonomic literature referring to axillary inflorescences are likely to be based on misinterpretations of the sympodial shoot structure. Nevertheless, the existence of short axillary shoots provided with a terminal inflorescence cannot be excluded. In such cases, however, the recognition of an axillary inflorescence would only depend on the extension of the proximal vegetative zone of the side branch.

In contrast to the descriptions in part of the taxonomic literature, not a single member of the Lasiopetaleae investigated exhibits racemes. Some inflorescences (e.g. in Thomasia) superficially resemble racemes but in fact are cincinni. There are cases in which the distinction between monopodia and monochasia is not obvious, but two characteristics provide arguments in favour of the latter interpretation: at least during early developmental stages, the flowers are oriented towards one side of the inflorescence, 
and the lack of a subtending bract beneath the first flower to open reveals its terminal position. Since the subtending bracts of the remaining flowers are displaced, the situation becomes complicated. Nevertheless, such inflorescences must not be called racemes, which would be misleading, when comparisons with other taxa are attempted.

In the inflorescences of Lasiopetalum (Classen 1988) and Keraudrenia, both monochasial and dichasial ramifications exist, whereas in Thomasia and other Lasiopetaleae, monochasia (cincinni) are found. The basic, fully ramified, dichasial form is found in Keraudrenia, which often is described as a terminal cyme (see, e.g., Hutchinson 1967, Jessop 1986). If structures such as those exemplified by K. hermanniifolia (Fig. 1) are meant, this is not correct, because in true cymes all ramifications arise from prophyllar axils. Since the terminal flower of a terminal inflorescence never has prophylls, the first order lateral flowers cannot arise from prophyllar axils. In this case, in which the partial inflorescences are cymose, the whole structure can be termed a cymoid (Troll 1964, Briggs \& Johnson 1979). Yet it differs from a 'normal' cymoid in the constant occurrence of an additional sterile bract which is incepted below the branching off of the lateral dichasia but ontogenetically is displaced distally beyond them. Sterile bracts in inflorescences are usually called 'Zwischenblätter' (Schumann 1890, Nordhagen 1937) or 'metaxyphylls' (Briggs \& Johnson 1979); they are known to occur in various determinate inflorescences (see Troll 1964) and are defined as phyllomes 'situated between the ultimate pherophyll(s) (or the prophylls) and the flower' (Briggs \& Johnson 1979: 244). However, the sterile bract in the inflorescence of Keraudrenia is different because it is situated between fertile phyllomes. Although it is a constant structure in the inflorescences of very many representatives of the Malvales (Bayer 1994), in this context and until we know more about its origin we refrain from creating a new term for it.

If we compare the cymoid of Keraudrenia with the monochasial inflorescence widespread in the Lasiopetaleae (exemplified in Fig. 3 B), again recaulescent shifts of the bracts are noticeable. It would, however, be grossly misleading to equate the fertile bracts on the axes bearing the main flowers of the inflorescences in Fig.s $1 \mathrm{~B}$ and $3 \mathrm{~B}$. Instead, the single 'supernumerary' sterile bract (a in Fig. 1) provides an appropriate fixed point for comparison. This allows recognition that the triad of bracts that form the epicalyx below flowers $1-4$ in Fig. $3 \mathrm{~B}$ correspond to the bracts a, b, c in Fig. 1. Thus, the epicalices of the flowers within monochasial inflorescences of Lasiopetaleae is hypothesized as having originated through the reduction of distal ramification (Fig. 4). The three appendages forming the epicalyx are individual, sterile bracts.

Indeed, distal ramifications including a supernumerary, sterile bract are typical of the inflorescences of the Sterculiaceae and Tiliaceae (Bayer 1994). In these families an increasing reduction of these ramifications is observed, which leads to flowers surrounded by a sterile epicalyx (Fig. 4 C). In Sterculiaceae (e.g. Dombeyeae, Fremontodendreae) and Tiliaceae, the occurrence of an epicalyx is considered as an advanced condition, while in the Malvaceae and Bombacaceae it appears to represent the basic character state (Bayer 1994).

Our interpretation of the epicalyx contrasts with the view of Classen (1988), according to which the epicalyx consists of a single leaf organ with its stipules. She preferred the latter interpretation in spite of having noted that the foliage leaves of Lasiopetalum are devoid of stipules and that the lateral appendages do not show the precocious development typical of stipules. If occasionally only a single bract is found beneath the flower (in some species of Lasiopetalum, Classen 1988), to our mind this corresponds to one of the three bracts of the Keraudrenia inflorescence. Therefore Classen's view (1988) that in Lasiopetalum the trimerous epicalyx is derived from a simple bract is rejected. 
It is well known that the delimitation of inflorescences in woody plants can be a most difficult task. This is even more true when the application of Troll's (1964) concept of synflorescences is attempted. This is not surprising, because Troll's concept was developed upon the study of predominantly herbaceous plants and in temperate regions (Briggs \& Johnson 1979), and the application of this concept to tropical woody plants is often difficult. If their growth is rhythmic, the growth flush may provide comparable units (Pilger 1922) and may serve to delimit synflorescences (Weberling 1983).

In Lasiopetalum, Classen (1988) tried to delimit synflorescences in accordance with the concepts of Troll (1964), selecting three different reiterative parts of the flowering region as units of reference: 1 . the module, which is the smallest recurrent unit; 2 . the seasonal growth unit (sensu Briggs \& Johnson 1979), which includes several modules; 3. the perennial flowering shoot including its basal vegetative portion and the seasonal growth units of several years. As a result, the description of the inflorescence necessarily depended on the extent of the unit chosen. However, the typological classification of the synflorescence remains unaffected since the flowering zone of Lasiopetalum (Classen 1988) and of other Lasiopetaleae can be characterized as monotelic in either of the three cases, even if the delimitation of a synflorescence is ambiguous.

\section{Systematic implications}

In a search for evidence for the assumption that the Lasiopetaleae are closely related to the Byttnerieae (Schumann 1895), a comparison of the inflorescence morphology in both tribes seems to be useful. There is a striking agreement in the position and structure of the inflorescences of Keraudrenia with those of Rulingia and Commersonia (Byttnerieae), each with displacements not only of the fertile bracts, but also of the sterile one. The correspondence is so far-reaching that the scheme of the inflorescence of Keraudrenia (Fig. 1) is virtually identical with one of Rulingia (see Bayer 1994: 34). It seems probable that this type of inflorescence, in which two of the three bracts that precede the terminal flower are fertile, represents the basic condition in Lasiopetaleae. The other type, found in Thomasia and other genera of the Lasiopetaleae, is supposed to be the derived condition. Jenny (1985) postulated relationships between Keraudrenia and Commersonia because of similarities in the structure of the gynoecium; according to him, Thomasia, Guichenotia and Lasiopetalum are farther derived because of their tendency towards a reduction of carpel and/or ovule number, their tubular stigma, and their anther dehiscence by pores or short slits. Another indication in favour of regarding the Lasiopetaleae as an advanced tribe of the Sterculiaceae-Byttnerioideae is the tendency towards reduction of the petals. This applies also to Rulingia and Commersonia, where short staminal tubes and reduced stamen numbers exist (Diels \& Pritzel 1904/1905). It is interesting to note that these genera include the only Australian representatives of the pantropical tribe Byttnerieae. In contrast, the Lasiopetaleae are of rather restricted distribution. According to Schumann (1895), they are endemic to Australia, with the exception of the monotypic genera Pimia (Fiji) and Seringia (New Guinea, Australia), and one species of Keraudrenia from Madagascar. All these facts would indicate that the Lasiopetaleae are derived from advanced Byttnerieae-like ancestors, but the analysis of their precise phylogenetic relationship is still an open problem. With regard to inflorescence morphology and other characters (anther dehiscence by longitudinal slits, presence of five carpels with free styles, numerous ovules, cf. Jenny 1985), Keraudrenia is one of the genera that have conserved several primitive states within the Lasiopetaleae. 


\section{References}

Baillon, H. (1870) Traité du dévelopment de la fleur et du fruit (suite), Buettnériées. Adansonia 9: $336-351$.

Bayer, C. (1994): Zur Infloreszenzmorphologie der Malvales. Diss. Bot. 212 (Cramer: Berlin, Stuttgart).

Bentham, G. \& Mueller, F. (1863): Sterculiaceae. Pp. 224-267 in Flora Australiensis, vol. 1 (Reeve \& Co.: London).

Briggs, B.G. \& Johnson, L.A.S. (1979) Evolution in the Myrtaceae - Evidence from inflorescence structure. Proc. Linn. Soc. New South Wales 102: 157-256.

Classen, R. (1988) Beiträge zur Kenntnis der Gattung Lasiopetalum (Sterculiaceae). Bot. Jahrb. Syst. 109: 501-527.

Diels, L. \& Pritzel, E. (1904/1905) Fragmenta phytographiae Australiae occidentalis. Bot. Jahrb. Syst. 35: 55-662.

Eichler, A.W. (1878) Blüthendiagramme, 2. Theil. (Engelmann: Leipzig; reprint Koeltz: Eppenheim 1954).

Gay, J. (1821) Monographie des cing genres de plantes que comprend la tribu des Lasiopetalées dans la famille des Büttneriacées. (Belin: Paris).

Hallé, F., Oldeman, R.A.A. \& Tomlinson, P.B. (1978) Tropical Trees and Forests: an Architectural analysis. (Springer: Berlin, Heidelberg, New York).

Hutchinson, J. (1967) The Genera of Flowering Plants (Angiospermae), vol. 2, (Clarendon: Oxford).

Jenny, M. (1985) Struktur, Funktion und systematische Bedeutung des Gynoeciums bei Sterculiaceen. Thesis Univ. Zürich.

Jessop, J.P. (1986) Sterculiaceae. Pp. 848-856 in Jessop, J.P. \& Toelken, H.R. (eds.), Flora of South Australia, part II, Leguminosae - Rubiaceae. 4. ed. (South Australian Government Printing Division: Adelaide).

Nordhagen, R. (1937) Studien über die monotypische Gattung Calluna Salisb. I. Bergens Museums Årbok, Naturoidensk. Rekke, 1937, Nr. 4: 1-55.

Patrick, S.J. (1993) Thomasia glabripetala (Sterculiaceae), a new species from south-west Western Australia. Nuytsia 9: 119-122.

Paust, S. (1974) Taxonomic studies in Thomasia and Lasiopetalum (Sterculiaceae). Nuytsia 4: $348-366$.

Payer, J.-B. (1857) Traité d'organogénie comparée de la fleur. (Masson: Paris; reprint Cramer: Lehre 1966).

Pilger, R. (1922) Ueber Verzweigung und Blütenstandsbildung bei den Holzgewächsen. Bibl. Bot. 90: 1-38.

Schumann, K. (1890) Neue Untersuchungen über den Blüthenanschluss. (Engelmann: Leipzig).

Schumann, K. (1895) Sterculiaceae. Pp. 69-99 in Engler, A. \& Prantl, K. (eds.): Die natürlichen Pflanzenfamilien, III. Teil, 6. Abt. (Engelmann: Leipzig).

Troll, W. (1964) Die Infloreszenzen. Typologie und Stellung im Aufbau des Vegetationskörpers, vol. 1. (Fischer: Stuttgart).

Weberling, F. (1983) Evolutionstendenzen bei Blütenständen. Akad. Wiss. Lit. Mainz, Abh. math.naturwiss. Kl. 1983, Nr. 1.

Weberling, F. (1989) Morphology of Flowers and Inflorescences. (Cambridge University Press: Cambridge.)

Wydler, H. (1878) Zur Morphologie, hauptsächlich der dichotomen Blüthenstände. Jahrb. wiss. Bot. 11: 313-379. 